\title{
28 Research Square \\ Transcriptomic Profiling of Cotton Leaves in Response to Cotton Aphid Attack
}

\author{
Jianmin Zhang \\ Yangtze University \\ Xiao Zhong \\ Yangtze University \\ Pei Feng \\ Yangtze University \\ Qiqi Ma \\ Yangtze University \\ Qi Su \\ Yangtze University \\ Xiangping phD Wang \\ Yangtze University \\ Yazhen Yang (D 371995966@qq.com ) \\ Yangtze University
}

\section{Research article}

Keywords: Gossypium hirsutum, Aphis gossypii Glover, RNA-Seq, Differentially expressed genes, Transcription factors, Aphid resistant genes

Posted Date: June 8th, 2019

DOI: https://doi.org/10.21203/rs.2.10118/v1

License: (c) (i) This work is licensed under a Creative Commons Attribution 4.0 International License.

Read Full License 


\section{Abstract}

Main conclusion The molecular mechanism of the interaction between cotton and cotton aphids remains unclear currently. The RNA-Seq study of cotton leaves was performed in response to cotton aphid damage at different time points. The transcriptome analysis revealed that a lot of cotton gene transcripts

were regulated by cotton aphid damage. Cotton aphids (Aphis gossypii Glover) are regarded as one of the most harmful insect pests for cotton production. They are usually capable of causing severe yield loss through sucking cotton liquids, secreting honeydews and transmitting plant viral diseases. However, the molecular mechanism of the interaction between cotton and cotton aphids remains unclear currently. Therefore, the RNA-Seq study of cotton leaves was performed in response to cotton aphid damage at different time points ( 0 h, 6 h, 12 h, 24 h, $48 \mathrm{~h}$ and $72 \mathrm{~h}$ ). A total of 9, 103 new genes were identified, and 7 , 510 of them were annotated functionally. Based on the comparison results, the gene expression was analyzed according to the expression amount of genes in different samples. 24,793 differentially expressed genes were authenticate in all and their functional annotation and enrichment analysis were conducted. Compared with $\mathrm{O} \mathrm{h}$ (without aphid damage, CK), the amount of down-regulated DEGs was largely more than that of the up-regulated genes at different time points under cotton aphid attack except for $48 \mathrm{~h}$. As revealed by the functional annotation of DEGs, these genes were involved in all kinds of plant biological process, including various resistance to abiotic and biotic stress, hormone metabolism, signaling transduction and transcriptional regulation. These results established a firm foundation for the study of the molecular mechanism of the interaction between cotton and cotton aphids and would facilitate the development of plant aphid resistant cultivars.

\section{Background}

Aphids are one of the common pests on almost all crops. They feed plant phloem sap with their piercingsucking mouthparts, which can have a direct impact on the normal growth and development of crops and eventually cause a severe loss of crop yield and quality. Compared with chewing insects, aphid feeding only causes relatively little mechanical injury to crops. However, the everlasting feeding of a large quantity of aphids usually consume a large amount of plant resources. Secondly, a lot of aphid species have the potential to spread plant viruses. For them, the detrimental effects caused by virus transmission are likely to outweigh the direct effects of aphid feeding. In addition, Honeydew secreted by aphids also gives rise to sooty mould on the leave surface to constrain leaf photosynthesis [1, 2]. To counter these damages, plants have developed a series of intricated mechanisms to combat against aphids. Plenty of studies have indicated that various changes occur in plants damaged by aphids, such as protein phosphorylation, calcium flux, reactive oxygen species (ROS) generation and phytohormone changes, which result in relevant transcriptional regulation in the early response to aphids. Finally, plants are capable of producing various defense compounds, including nutrient compounds, glutathione $S$ transferases (GSTs), peroxidases, and secondary metabolites for the sake of self defense [3]. Overall, plant susceptibility or resistance to aphids is reliant on their ability to recognize aphid feeding and rapidly initiate defense response [4]. 
Plant resistance is considered as one of the most effective ways of achieving plant health management at the present time and in the near future [5]. Therefore, constantly exploring new aphid resistant genes has been a long-standing hot topic for scientists. Mi-1.2 from the tomato was discovered to contribute to resistance to Macrosiphum euphorbiae and Bemisia tabaci [6, 7]. The melon gene Vat was reported to safeguard against virus aphid transmission and Aphis gossypii Glover [8]. Both of them are the earlier known aphid resistance genes and fall into NBS-LRR family, indicating that the NBS-LRR family members perform a significant part in plant aphid resistance. Lectin was also proved to perform resistance to aphids. For instance, The Galanthus nivalis agglutinin (GNA) gene encoding a monocot mannose-binding is extensively and clearly documented to confer resistance to Myzus persicae [9]. The Amaranthus caudatus agglutinin (ACA) gene confers resistance to Aphis gossypii and Myzus persicae [10, 11]. In addition, the other aphid resistant genes, including Rag, chitinase, \-amylase and on the likes, are researched actively and widely [12].

RNA-Seq is a robust technology for analyzing transcriptome and excavating new functional genes. Therefore, it is taken advantage of for many fields including plant defense response to phytophagous insects [13]. For instance, the changes in gene expression in the whole genome of the cucumber aphid resistant cultivar 'EP6392' were monitored using an Illumina Genome Analyzer platform [14]. Furthermore, a comprehensive insect resistance response mechanism in cotton infested by the phloem feeding insect Bemisia tabaci was discovered through Transcriptome analysis [15]. In addition, the transcriptome analyses of Gossypium hirsutum at $24 \mathrm{~h}$ and $48 \mathrm{~h}$ in response to aphid and whitefly were conducted comparatively [16]. However, compared to other research areas, RNA-Seq analyses of plant defense response to phytophagous insects have been relatively sporadic up to now.

As an essential economic crop, the recent research on cotton transcriptome characterization is focused on comparative transcriptomic analysis at different growth stages and under all sorts of stresses. For instance, many new genes of cotton fiber were extensively analyzed from different angles using RNA-Seq method [17-21]. Furthermore, cotton RNA-Seq data were also analyzed under various abiotic stress, such as salt stress [22-25], dry stress [26-27] \and high temperature stress [28]. Cotton is also attacked by all kinds of biotic factors, such as Cotton Verticillium wilt. As one of the most destructive cotton diseases, the study on Cotton Verticillium wilt using RNA-Seq is concerned widely. For example, RNA-Seq transcriptional analysis and histo-chemistry have illustrated that lignin metabolism plays an important role in the cotton resistance to Verticillium dahlia [29]. The gene families of resistance gene analogues in cotton and their response to Verticillium wilt is also studied [30]. The analysis of sea-island cotton and upland cotton in response to the damage of Verticillium dahliaewas was conducted using RNA-Seq [31]. However, RNA-Seq has rarely been applied to research the interaction between cotton and herbivorous insects.

It is known that using cotton aphid resistance for aphid control is both most effective and eco-friendly. Therefore, the analysis of the transcriptome dynamics of cotton defense response to cotton aphid damage was conducted using the RNA-Seq method for a better understanding of cotton aphid resistance mechanism. Our research will lay a solid foundation for further research into the molecular mechanism of 
the interaction between cotton and aphids, searching for new cotton aphid resistant genes and developing new cotton aphid resistant varieties.

\section{Results}

RNA-Seq outline of cotton leaves in response to cotton aphid attack

The damage caused by cotton aphids is rated as the serious at seedling stage during the growth and development of cotton. Therefore, the cotton leaves at the four-leaf stage were selected as the research material. To excavate the crucial genes at the transcriptional level in cotton defense response to cotton aphid damage, the whole-transcriptome RNA sequencings of cotton leaves at 0 (without aphid damage, CK), 6, 12, 24, 48 and $72 \mathrm{~h}$ under sustained cotton aphid attack were performed respectively. After filtering out reads containing adapter or ploy- $\mathrm{N}$, and low-quality sequences, there were $60.05,58.70,57.74,65.73$, 59.80 , and 60.26 million clean reads with pair-end $\left(Q_{30}>85.03 \%, G C \%=41.3-42.9 \%\right)$ respectively produced by RNA-Seq in all the six libraries (Supplementary Table S2). For the clean reads according to the singleend, $89.94-90.78 \%$ of them were mapped to the cotton reference genome sequence (Supplementary Table S3). The mapped reads were spliced with Cufflinks software, and compared with the original genome annotation information to explore the original unannotated transcription area and excavate the new transcripts and new genes. A total of 79,581 unigenes were identified by filtering out sequences that were comprised of less than 50 amino acid residues or only a single exon. To obtain the annotation information of the new genes, the databases was analyzed using a combination of BLAST [32], NR, GO, KEGG, COG and Swiss-Prot. A total of 9,103 new genes were discovered, of which 7,510 were functionally annotated (Tab. 1). The normalized FPKM was used to quantify the gene expression level [33]. The transcript expression level (FPKM) in this study ranged from $10^{-2}$ to $10^{4}$, which was found to be coherent with most of the RNA-Seq results (Fig. 1A). FPKM boxplot analysis demonstrated that the gene transcript expression levels varied in the six RNA-Seq data to some extent (Fig. 1B).

Differentially expressed genes from cotton leaves under cotton aphid attack

As gene expression has time specificity, it is quite significant to study the cotton differentially expressed genes (DEGs) at different stages under cotton aphid attack. Each sample damaged by cotton aphids was compared with the control $(0 \mathrm{~h})$ to identify differentially expressed genes $(6 \mathrm{~h}$ vs. Control, $12 \mathrm{~h}$ vs. Control, $24 \mathrm{~h}$ vs. Control, $48 \mathrm{~h}$ vs. Control and $72 \mathrm{~h}$ vs. Control). Fold Change $\geq 2$ and FDR $<0.05$ was taken as the screening criteria. From these pairwise comparisons drawn with the control sample, we identified 5,790 (2,580 up- and 3,210 down-regulated) , 9,726 (3,452up- and 6,274 down-regulated), 5,279(1,836up- and 3,443 down-regulated), 4,549(2,477 up- and 2,072 down-regulated) and 8,683(2,769 up- and 5,914 downregulated) DEGs respectively after $6 \mathrm{~h}, 12 \mathrm{~h}, 24,48 \mathrm{~h}$, and $72 \mathrm{~h}$ under cotton aphid attack $\mathrm{Fig}$. 2A, Supplementary Table S4). The differentially expressed genes were analyzed by means of hierarchical clustering, and the genes with the same or similar expression patterns were clustered (Fig. 2B). In addition, it was discovered that the DEGs between cotton aphid attack (48 $\mathrm{h}$ ) and CKख0 h囚is distinct from 
the other treats. The amount of up-regulated genes was higher than that of down-regulated genes

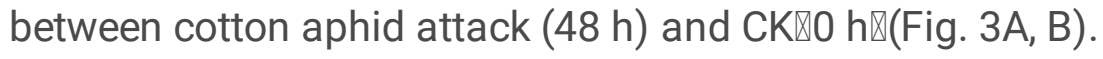

DEG functional classification

The DEGs between cotton aphid attack ( $6 \mathrm{~h}, 12 \mathrm{~h}, 24 \mathrm{~h}, 48 \mathrm{~h}$, and $72 \mathrm{~h}$ ) and CKख0 hषwere subjected to GO term enrichment analysis, involving cellular component, molecular function and biological function. The results indicated that plenty of DEGs was associated with biotic or abiotic stress, including response to salt stress (1734), response to chitin (1245), defense response to bacterium (1230), response to cold (1199), response to fungi (1196), response to wounding (1194), response to water deprivation (1349), response to abscisic acid (1292), and response to cadmium ion (1496) (Fig. 4A囚Supplementary Table S5). Additionally, it is noteworthy that two genes in the "response to insect (GO: 0009625)" and "defense response to insect (GO: 0002213)" was enriched during the biological process. To carry out a further investigation into the biological functions performed by these DEGs, pathway-based analysis was conducted using KEGG. Totally 126 pathways were identified that were significantly enriched in comparisons of cotton aphid attack $(6 \mathrm{~h}, 12 \mathrm{~h}, 24 \mathrm{~h}, 48 \mathrm{~h}$, and $72 \mathrm{~h}$ ) versus CKखO h囚, such as plant hormone signal transduction (378)『starch and sucrose metabolism (244), ribosome (236), carbon metabolism (307), biosynthesis of amino acids (275), pyruvate metabolism (125), carbon fixation in photosynthetic organisms (123), endocytosis (114), glutathione metabolism (119), pyrimidine metabolism (117), pentose and glucoronate interconversions (99), RNA degradation (94), fatty acid metabolism (93), arginine and proline metabolism (98), mRNA surveillance pathway (97), glycerophospholipid metabolism (98), RNA transport (103), cysteine and methionine metabolism (100), glyoxylate and dicarboxylate metabolism (106), phagosome (104), glycine, serine and threonine metabolism (104), peroxisome (103), photosynthesis (191), plant-pathogen interaction (176), Purine metabolism (169), amino sugar and nucleotide sugar metabolism (168), phenylpropanoid biosynthesis (141), oxidative phosphorylation (155), protein processing in endoplasmic reticulum (156), and glycolysis / gluconeogenesis (155) (Fig. 4B).

Differentially expressed transcription factors involved in response to cotton aphid stress

Transcription factors (TFs) are a specific DNA-binding protein that have regulatory functions at transcription level and performs an essential role in plant growth and development. In this study, a total of 945 Differentially expressed transcription factors $\triangle T F s \rrbracket$ were identified from cotton leaf response to cotton aphids. They were classed into 27 TF families respectively (Supplementary Table S6). A large majority of them encoded the members of the bHLH, MYB, WRKY, ERF, bZIP, TCP and NAC TF families (Fig. 5A). The bHLH family with 199 DEGs was rated as the largest TF family in cotton leaf response to cotton aphid stresses. In addition, a total of 152 DEGs were identified to belong to the MYB family. The expression levels for many of the differentially expressed TFs were up-regulated under cotton aphid attack, especially at 48 and $72 \mathrm{~h}$ under cotton aphid attack. However, the transcripts of some differentially expressed TFs were down-regulated, indicating that the functions carried out by cotton TF were complex in cotton response to cotton aphid attack (Fig. 5B). 
Differentially expressed aphid-resistant genes involved in response to cotton aphid stress

Aphid damage often triggers the differentially expressed genes related to plant resistance, involving plant morphological resistance, phytoprotective enzyme and SA, JA and ethylene signal pathway. Plenty of plant aphid resistance genes were identified at first in this study. For example, a total of 422 LRR genes were identified at first, of which 19 belonged to NBS-LRR proteins associated with the detection of bacteria, viruses, fungi, nematodes, insects and oomycetes. Besides, 90 Leucine-rich repeat receptor-like protein kinase were founded (Supplementary Table S7). 140 lectin genes were discovered in our RNA-Seq data and 10 genes of them were regarded as cotton new genes. Compared to the expression levels without cotton aphid attack $₫ 0 \mathrm{~h}$ ), the expression levels of most lectin genes were up-regulated at $6,12,24$, 48 and $72 \mathrm{~h}$, and only transcription of two lectin gene were down-regulated (Fig. 6A凶B). There were some other aphid resistant genes involved in this study, including 72 form aphid resistant genes related to callose and trichomes, as well as 81 plant protective enzyme gene relative to peroxidase邓phenylalanine ammonialyase and polyphenol oxidase.

Verification of RNA-Seq data by qPCR

To validate the results of the RNA-Seq, ten random DEGs including five up-regulated and five downregulated genes were selected to perform qPCR. The selected genes were successfully amplified and the products were of the expected size, indicating the reliability of the assembly work. The qPCR results demonstrated that the relative expression levels of ten selected genes were consistent with the results of RNA-Seq despite the differential expression folds, suggesting that the RNA-Seq data were highly reliable (Fig. 7).

\section{Discussion}

RNA-Seq presents an effective way for the identification of DEGs and their regulatory mechanisms at the transcriptome level [34]. It could provide new insights into the molecular basis for plant response to all kinds of abiotic and biotic stresses [35-37].

RNA-Seq in cotton response to cotton aphid damage

Aphids are the largest group of the phloem-feeding insects and often cause severe economic losses in crop production. However, the mechanism for the interplay between plant and aphids remains unclear at the moment [1]. Therefore, there is great significance for understanding their interaction mechanism to study the cotton response to cotton aphid damage using RNA-Seq method. Dubey et al. (2013) carried out the comparative transcriptome analysis of Gossypium hirsutum in response to aphids and whiteflies [38]. However, only the transcriptomes of cotton infested with aphids and whiteflies for $2 \mathrm{~h}$ and $24 \mathrm{~h}$ were sequenced and analyzed. In this study, the RNA-Seq data of cotton leaves at $0,6,12,24,48$, and $72 \mathrm{~h}$ under the attack of cotton aphids was analyzed. The sequencing results suggested that a total of 9,103 new genes were discovered and 7, 510 were annotated functionally at different time points. Based on the comparison results, the gene expression was analyzed in accordance with the expression amount of 
genes in different samples. 24,793 DEGs were authenticated in all and their functional annotation and enrichment analysis were performed. The number of down-regulated DEGs was found out to be largely higher than that of the upregulated genes at different time under cotton aphid attack, which was in line with the previous studies that infestations of whiteflies and aphids drove transcriptional suppression over induction $[39,38]$. However, the number of down-regulated DEGs was slightly smaller than that of the upregulated genes at $48 \mathrm{~h}$ under cotton aphid attack in this study. Functional annotation of DEGs led to a finding that these genes were involved in a lot of plant biological processes, including all sort of resistance to abiotic and biotic stress, hormone metabolism, signaling transduction and transcriptional regulation. However, there were only two genes in the "response to insect (G0: 0009625)" and the "defense response to insect (GO: 0002213)" was enriched in biological process, which suggested that study on plant response to insects should be enforced.

\section{Plant aphid resistant genes}

Plant defenses against aphids are initiated at various levels of their interplay with aphids [40]. Firstly, plant surface is the first barrier of aphid feeding and activities, such as thorn and glandular trichomes on the surface of plant [41-43]. In our study, 12 DEGs (Protein WAX2 or Protein WAX2 -like protein) were identified, and these DEG expressed levels varied at 6, 12, 24, 48 and 72h after cotton aphid attack in comparison with the CK Control $(0 \mathrm{~h})$. Trichomes on the surface of plant could also exert impact on aphid activities by hindering aphid movement. Furthermore, glandular trichomes are usually an origin of sugar esters and secondary metabolites that are harmful to insects [44, 45]. Some glandular trichomes even have the potential to release the aphid alarm pheromone, such as (E)- $\beta$-farnesene [46]. Our data analysis showed a total of 51 differentially expressed genes on trichomes were identified and 3 DEGs of them were reported at first, suggesting that trichomes were crucial to plant aphid resistance. In addition, plants inhibit the afflux of phloem inclusion into the aphid by facilitating sieving element occlusion (SEO). SEO includes two processes: a rapid formation of proteinaceous plugs that transiently seal sieve plates and a slower callose deposition that causes long-term occlusion of sieve tubes [47]. A total of 20 DEGs on callose deposition were also identified in this study. Three of them were reported at first. These results indicated that callose was involved in cotton response to cotton aphid attack.

Some loci with specific aphid resistance have been stated in many plants, but only the Mi-1.2 gene from tomato and the Vat gene from melon have been cloned. They contribute to resistance against Macrosiphum euphorbiae and Aphis gossypii respectively [6, 48, 49]. They belong to coiled-coil nucleotide-binding site -leucine-rich repeat type proteins (CC-NBS-LRR). In our study, a total of 422 LRR genes were identified, 19 of which were classed into NBS-LRR proteins. Besides, 90 Leucine-rich repeat receptor-like protein kinase were identified. The carbohydrate-binding protein lectins exist in many plants and perform important functions in guarding plants against insect pests. At the moment, many lectin genes from plant have been transferred to plants to improve resistance to many phloem insects [50]. The agglutinin gene is the most widely studied for plant resistance to aphid as the carbohydrate-binding proteins currently. 140 lectin genes were discovered in our RNA-Seq data and 10 genes of them were considered as cotton new genes. When compared to expression levels without cotton aphid attack at $0 \mathrm{~h}$ ), 
the expression levels of most of lectin genes was up-regulated at 6 h, 12 h, $24 h, 48$ h, and $72 \mathrm{~h}$, only transcription of two lectin gene were down-regulated. Plenty of other aphid resistant genes were also involved in this study, including 81 plant protective enzyme genes relative to peroxidase $₫$ phenylalanine ammonialyase, polyphenol oxidase and on the likes.

Transcription factors involved in response to cotton aphid stress

Some transcription factors in plant have been validated to act as a key role in the face of the attack by herbivorous insects.For example, overexpressing CmMYB19 improved aphid tolerance in Chrysanthemum by facilitating lignin production [51]. Similarly, three MYB genes were related to the wheat defense against English grain aphid [52]. In addition, overexpression of GsMYB15 from the wild Soybean R2R3 enhanced resistance to Helicoverpa Armigera in Arabidopsis [53]. However, myb102 from Arabidopsis increased plant susceptibility to aphids by substantial activation of ethylene biosynthesis [54]. A total of 152 DEGs belonging to the MYB family were identified in this study. The functions of them need to be further verified through relative experiments. Some members of the WRKY family are reported for aphid resistance. For instance, the overexpression of a chrysanthemum WRKY transcription factor enhanced aphid resistance [55]. However, AtWRKY22 from Arabidopsis increased Arabidopsis susceptibility to aphids and modulated SA and JA signaling [56]. In addition, the rice WRKY53 suppressed herbivoreinduced defenses by acting as a negative feedback modulator of map kinase activity [57]. In short, the functions of transcription factors in plant response to aphids are relative complex. Studies of cotton transcription factors are primarily focused on fiber development and the response to all kinds of abiotic stress at present. Therefore, studies of their aphid resistance should be performed continuously in the future.

Plant defense signaling in cotton response to cotton aphids

The plant hormones (salicylic acid, jasmonic acid, ethylene and abscisic acid) lead to signaling related to plant-aphid interaction. Despite the aphid effectors remain to be identified, important advances have been acquired in comprehending the signaling machinery related with Mi-1.2 in tomato. Some genes in ETI to microbes are also required for Mi-1.2-conferred resistance to Macrosiphum euphorbiae. Such as Heat shock protein 90 and Suppressor of G-two allele of Skp1 [58]. A receptor-like kinase encoded by the tomato SERK1, a mitogen-activated protein kinase cascade and the transcription factors WRKY70 and WRKY72 are also required for Mi-1.2 resistance to aphids [59-61]. $\mathrm{Ca}^{2+}$ functions as a secondary messenger in eukaryotes. It is universally thought that $\mathrm{Ca}^{2+}$ could influence callose deposition, promote phloem protein aggregation and result in phloem occusion [62-64]. $253 \mathrm{DEGs}$ on $\mathrm{Ca}^{2+}$ were identified in this study, and 93 DEGs were associated with inorganic ion transport and metabolism, suggesting that $\mathrm{ca}^{2+}$ was essential in cotton response to cotton aphids. PAD4 is obligatory for restricting insect feeding from the sieve elements and hindering callose deposition $[65,66]$. Furthermore, PAD4 facilitates premature leaf senescence in aphid-damaged leaves, which is harmful for the insect in term of leaf nutrition [67]. PAD4 is relative to plant defense reponse to pathogens. However, PAD4 functions in plant defense to aphids are distinct from their ones in defense to pathogens [68-70]. 
In the present study, RNA-Seq was applied for detection of the global transcriptional changes in seedling cotton leaves in response to cotton aphid attack. A total of 9, 103 new genes were identified and 7, 510 were annotated functionally. Crucially, 24,793 DEGs were commonly identified in response to cotton aphids, suggesting that there were plenty of common and unique molecular mechanisms in relation to the response to cotton aphid stresses in cotton. This study extends the understanding of the molecular mechanisms for cotton leaf resistance to cotton aphids in the seedling stage and facilitates the development of plant aphid resistant cultivars.

\section{Methods}

Plant materials

Red-leaf cotton (Gossypium hirsutum), an aphid-resistant cotton cultivar, was provided by the Institute of Cotton from Chinese Academy of Agricultural Sciences. At first囚its seeds were sown directly in 30-cmdiameter plastic pots filled with nutrient soil until the seedling grew to 4 leaves in a growth room $\left(25^{\circ} \mathrm{C}\right.$, $16 \mathrm{~h}$ light/8 $\mathrm{h}$ dark). The leaves were collected respectively without cotton aphid damage (0 h, CK) and at $6,12,24,48$ and $72 \mathrm{~h}$ under the attack of cotton aphids (Aphis gossypii), transferred quickly into liquid nitrogen for 1 min囚and stored in the ultra-low temperature freezer.

\section{Library construction and sequencing}

Total RNA from each sample was isolated using Trizol method. $1.5 \mu \mathrm{g}$ RNA from each sample was used as input material for the removal of rRNA utilizing the Ribo-Zero rRNA Removal Kit (Epicentre, Madison, WI, USA). The libraries for sequencing were established with NEBNext ${ }^{R}$ Ultra $^{T M}$ Directional RNA Library Prep Kit for Illumina ${ }^{R}$ (NEB, Ipswich, USA). The index codes were appended to attribute sequences to each sample. The quality of the library was estimated using the Agilent Bioanalyzer 2100 and qPCR method. The clustering of each index-coded sample was executed on acBot Cluster Generation System using TruSeq PE Cluster Kitv3-cBot-HS (Illumia). After cluster generation, the library preparations were sequenced on an Illumina Hiseq platform and 150-200 paired-end reads were derived.

\section{Transcriptome assembly}

Raw reads were pre-processed for quality filtering where reads including adapter or ploy-N, and low quality reads were cleaned. According to the reference genome, the mapped reads were spliced using Cufflinks software. The original unannotated transcription area was searched, and new transcripts and new genes were excavated in order to supplement and perfect the original genome annotation information. The sequences that are less than 50 amino acid residues or that contain only a single exon were filtered out.

Differentially expressed gene analysis 
Gene FPKMs (fragments per kilo-base of exon per million fragments) were calculated by summing the FPKMs of transcripts in each gene group. FPKMs of coding genes in each sample were computed using StringTie (1.3.1). EBSeq was employed for difference analysis [71]. During the course of differentially expressed gene detection, Fold Change $\geq 2$ and False Discovery Rate $\triangle F D R \rrbracket<0.05$ served as the screening criteria. Fold Change represents the ratio of expression quantity between two treats. FDR is determined through the p-value correction of different significance.

Functional annotations of differentially expressed genes

The functions of differentially expressed genes were annotated with NR [72], swiss-prot [73], GO [74], COG [75] and KEGG [76]. In order to obtain the annotation information about the new genes, the reference Gossypium hirsutum genome and the annotation files were downloaded from the CottonGen database (http://www.cottongen.org).

Quantitative real-time PCR

To ascertain the expression level of ten genes, quantitative real-time PCR (qPCR) was carried out based on the manufacturer's guides for the Bio-Rad CFX 96 Real-Time Detection System (Bio-Rad, Hercules, CA, USA) and the SYBR premix ex Taq II system (Takara perfect real time). Cotton leaves were firstly collected without cotton aphid damage $(0 \mathrm{~h}, \mathrm{CK})$ and at $6,12,24,48$, and $72 \mathrm{~h}$ under cotton aphid attack at the four-leaf stage. Total RNA was isolated from each sample and reversely transcribed into cDNA as qPCR template. The expression profiles of the relative genes were examined through qPCR method. All reactions were conducted in triplicate, and controls were included. The $2^{-\triangle} \triangle \mathrm{Ct}$ method was applied to the calculation of relative gene expression values [77]. The prime sequence was presented in Supplementary Table S1.

\section{Declarations}

Acknowledgments

The authors thank Prof. Chuanren Li (College of Agriculture, Yangtze University, Jingzhou, China) for providing the advices.

Funding

This work was supported by grants from the National Natural Science Foundation of China (Grant No. 31471783).

Availability of data and materials

The datasets of this publication are included within the article and its Additional files.

Authors' contributions

Page 10/23 
ZJM and YYZ conceived and designed the research. ZX, FP, MQQ performed the experiments, ZJM analyzed the data and wrote the manuscript. SQ and WXP revised the manuscript.

Ethics approval and consent to participate

Not applicable.

Consent for publication

Not applicable.

Competing interests

The authors declare that they have no competing interests.

Publisher's Note

Springer Nature remains neutral with regard to jurisdictional claims in published maps and institutional affiliations.

Author details

Institute of Entomology, College of Agriculture, Yangtze University, Jingzhou, Hubei, 434025, China.; College of Life Sciences, Yangtze University, Jingzhou, Hubei, 434025, China.

\section{References}

1. Züst T, Agrawal AA (2016). Mechanisms and evolution of plant resistance to aphids. Nat plants 2:19.

2. Ng JC, Perry KL (2004) Transmission of plant viruses by aphid vectors. Mol Plant Pathol5: 505-511.

3. Douglas AE (2018) Strategies for enhanced crop resistance to insect pests. Annu Rev Plant Biol 69: 637-660.

4. Will T, Furch AC, Zimmermann MR (2013) How phloem-feeding insects face the challenge of phloemlocated defenses. Front Plant Sci4: 1-2.

5. Will T, Furch AC, Zimmermann MR (2013) How phloem-feeding insects face the challenge of phloemlocated defenses. Front Plant Sci4: 1-2.

6. Rossi M, Goggin FL, Milligan SB, Kaloshian I, Ullman DE, Williamson VM (1998) The nematode resistance gene $\mathrm{Mi}$ of tomato confers resistance against the potato aphid, Proc Natl Acad Sci USA95: 9750-9754.

7. Nombela G, Williamson VM, Muñiz M (2003) The root-knot nematode resistance gene Mi-1.2 of tomato is responsible for resistance against the whitefly Benisia tabaci. Mol Plant Microbe In 16: 645-649. 
8. Nombela G, Williamson VM, Muñiz M (2003) The root-knot nematode resistance gene Mi-1.2 of tomato is responsible for resistance against the whitefly Benisia tabaci. Mol Plant Microbe In 16: 645-649.

9. Nombela G, Williamson VM, Muñiz M (2003) The root-knot nematode resistance gene Mi-1.2 of tomato is responsible for resistance against the whitefly Benisia tabaci. Mol Plant Microbe In 16: 645-649.

10. Wu J, Luo X, Guo H, Xiao J, Tian Y (2006) Transgenic cotton, expressing Amaranthus caudatus agglutinin, confers enhanced resistance to aphids. Plant Breeding 125: 390-394.

11. Guo HN, Jia YT, Zhou YG., Zhang ZS, Ouyang Q, Jiang Y, Tian YC (2004) Effects of transgenic tobacco plants expressing ACA gene from Amaranthus caudatus on the population development of Myzus persicae. ActaBot Sin 46: 1100-1105.

12. Yates, A. D, Michel A, (2018) Mechanisms of aphid adaptation to host plant resistance. Curr Opin Insect Sci26: 41-49.

13. Rai MF, Tycksen ED, Sandell LJ, Brophy RH (2018) Advantages of RNA-seq compared to RNA microarrays for transcriptome profiling of anterior cruciate ligament tears. J Orthop Res 36: 484-497.

14. Rai MF, Tycksen ED, Sandell LJ, Brophy RH (2018) Advantages of RNA-seq compared to RNA microarrays for transcriptome profiling of anterior cruciate ligament tears. J Orthop Res 36: 484-497.

15. Rai MF, Tycksen ED, Sandell LJ, Brophy RH (2018) Advantages of RNA-seq compared to RNA microarrays for transcriptome profiling of anterior cruciate ligament tears. J Orthop Res 36: 484-497.

16. Rai MF, Tycksen ED, Sandell LJ, Brophy RH (2018) Advantages of RNA-seq compared to RNA microarrays for transcriptome profiling of anterior cruciate ligament tears. J Orthop Res 36: 484-497.

17. Yoo MJ, Wendel JF (2014) Comparative evolutionary and developmental dynamics of the cotton (Gossypium hirsutum) fiber transcriptome. Plos Genet. 10: 1-19.

18. Yang SS, Cheung F, Lee JJ, Ha M, Wei NE, Sze S (2006) Accumulation of genome-specific transcripts, transcription factors and phytohormonal regulators during early stages of fiber cell development in allotetraploid cotton. The Plant J47: 761-775.

19. Yang SS, Cheung F, Lee JJ, Ha M, Wei NE, Sze S (2006) Accumulation of genome-specific transcripts, transcription factors and phytohormonal regulators during early stages of fiber cell development in allotetraploid cotton. The Plant J47: 761-775.

20. Liu D, Zhang J, Liu X, Wang W, Liu D, Teng Z (2016) Fine mapping and RNA-Seq unravels candidate genes for a major QTL controlling multiple fiber quality traits at the $T 1$ region in upland cotton. BMC genomics 17: 1-13.

21. Ma Q, Wu M, Pei W, Wang X, Zhai H, Wang W (2016) RNA-seq-mediated transcriptome analysis of a fiberless mutant cotton and its possible origin based on SNP markers. PLOS one 11: 1-13.

22. Peng Z, He S, Gong W, Sun J, Pan Z (2014) Comprehensive analysis of differentially expressed genes and transcriptional regulation induced by salt stress in two contrasting cotton genotypes. BMC genomics 15: 1-28. 
23. Shu HM, Guo SQ, Gong YY, Jiang L, Zhu JW, Ni WC (2017) RNA-seq analysis reveals a key role of brassinolide-regulated pathways in NaCl-stressed cotton. Biol Plantarum 61: 667-674.

24. Zhang F, Zhu G, Du L, Shang X, Cheng C, Yang B (2016). Genetic regulation of salt stress tolerance revealed by RNA-Seq in cotton diploid wild species, Gossypium davidsonii. Sci. Reports 6: 1-15.

25. Zhu G, Li W, Zhang F, Guo W (2018). RNA-seq analysis reveals alternative splicing under salt stress in cotton, Gossypium davidsonii. BMC genomics, 19: 1-15.

26. Bowman, MJ, Park W, Bauer PJ, Udall JA, Page JT, Raney J, Scheffler Jones DC, Campbell BT (2013) RNA-Seq transcriptome profiling of upland cotton (Gossypium hirsutum L.) root tissue under waterdeficit stress. Plos One 8: 1-28.

27. Fracasso A, Trindade LM, Amaducci S (2016) Drought stress tolerance strategies revealed by RNASeq in two sorghum genotypes with contrasting WUE. BMCPlant Boil 16: 1-18, 115.

28. Min L, Li Y, Hu Q, Zhu L, Gao W (2014) Sugar and auxin signaling pathways respond to high temperature stress during anther development as revealed by

29. Xu L, Zhu L, Tu L, Liu L, Yuan D, Jin L, Jin L, Long L, Zhang XL (2011) Lignin metabolism has a central role in the resistance of cotton to the wilt fungus Verticillium dahliae as revealed by RNA-Seqdependent transcriptional analysis and histochemistry. J Exp Bot 62: 5607-5621.

30. Chen JY, Huang JQ, Li NY, Ma XF, Wang JL (2015) Genome-wide analysis of the gene families of resistance gene analogues in cotton and their response to Verticillium wilt. BMC Plant Boil. 15: 1-15.

31. Sun Q, Jiang H, Zhu X, Wang W, He X (2013) Analysis of sea-island cotton and upland cotton in response to Verticillium dahliae infection by RNA sequencing. BMC Genomics 14: 1-13

32. Altschul SF, Madden TL, Schäffer AA, Zhang J, Zhang Z, Miller W, Lipman D (1997) Gapped BLAST and PSI-BLAST: a new generation of protein database search programs. Nucleic Acids Res 25: 33893402.

33. Trapnell C, Williams BA, Pertea G, Mortazavi A, Kwan G, van Baren MJ, Salzberg SL, Wold BJ, Pachter $L$ (2010) Transcript assembly and quantification by RNA-Seq reveals unannotated transcripts and isoform switching during cell differentiation.Nat Biotechnol 28: 511-515.

34. Wang Z, Gerstein M, Snyder M (2009). RNA-Seq: a revolutionary tool for transcriptomics. Nat Rev Genet 10: 57-63..

35. Sjokvist E, Lemcke R, Kamble M, Turner F, Blaxter M, Havis NH, Lyngkjær MF, Radutoiu S (2019) Dissection of Ramularia leaf spot disease by integrated analysis of barley and Ramularia collocygni transcriptome responses. Mol Plant Microbe In 32: 176-193.

36. Ashoub A, Müller N, Jiménez-Gómez JM, Brüggemann W (2018) Prominent alterations of wild barley leaf transcriptome in response to individual and combined drought acclimation and heat shock conditions. Physiol Plantarum 163: 18-29.

37. Janiak A, Kwasniewski M, Sowa M, Gajek K, Żmuda K, Kościelniak J, Szarejko I (2018) No time to waste: transcriptome study reveals that drought tolerance in barley may be attributed to stressed-like expression patterns that exist before the occurrence of stress.Front Plant Sci 8: 1-25. 
38. Dubey NK, Goel R, Ranjan A, Idris A, Singh SK, Bag SK, et al. (2013). Comparative transcriptome analysis of Gossypium hirsutum L. in response to sap sucking insects: aphid and whitefly. BMC Genom 14: 1-20.

39. De Vos M, Van Oosten VR, Van Poecke RM, Van Pelt JA, Pozo MJ, Mueller MJ, et al. (2005) Signal signature and transcriptome changes of Arabidopsis during pathogen and insect attack. Mol Plant Microbe Interact 18: 923-937.

40. Douglas A (1998) Nutritional interactions in insect-microbial symbioses: aphids and their symbiotic bacteria Buchnera Annu Rev Entomol 43: 17-37.

41. Wójcicka A (2015) Surface waxes as a plant defense barrier towards grain aphid. Acta Biol Cracoviensia S Bot57: 95-103.

42. Stoner KA (1990) Glossy leaf wax and plant resistance to insects in Brassica oleracea under natural infestation. Environ Entomol 19: 730-739.

43. Ellis PR, Singh R, Pink DAC, Lynn JR, Saw PL (1996) Resistance to Brevicoryne brassicae in horticultural brassicas. Euphytica 88: 85-96.

44. Glas J, Schimmel B, Alba J, Escobar-Bravo R, Schuurink R, Kant M (2012) Plant glandular trichomes as targets for breeding or engineering of resistance to herbivores. Int J Mol Sci13: 17077-17103.

45. Goffreda JC, Steffens JC, Mutschler MA (1990) Association of epicuticular sugars with aphid resistance in hybrids with wild tomato. J Am Soc Hort Sci 115: 161-165.

46. Gibson RW, Pickett JA (1983) Wild potato repels aphids by release of aphid alarm pheromone. Nature 302: 608-609.

47. Verma DPS, Hong Z (2001) Plant callose synthase complexes, Plant Mol Biol 47: 693-701.

48. Vos P, Simons G, Jesse T, Wijbrandi J, Heinen L, Hogers R, Hogers R, Frijters A, Groenendijk J, Diergaarde P, Reijans M, Fierens-Onstenk J, de Both N, Peleman J, Liharska T, Hontelez J, Zabeau M (1998) The tomato Mi-1 gene confers resistance to both root-knot nematodes and potato aphids.Nat Biotech 16: 1365-1369.

49. Dogimont C, Chovelon V, Pauque, J, Boualem A, Bendahmane A (2014) The Vat locus encodes for A CC-NBS-LRR protein that confers resistance to Aphis gossypii infestation and A. gossypii-mediated virus resistance. Plant J 80: 993-1004.

50. Duan X, Hou Q, Liu G, Pang X, Niu Z, Wang X (2018) Expression of Pinellia pedatisecta Lectin Gene in Transgenic Wheat Enhances Resistance to Wheat Aphids. Molecules 23:1-10.

51. Wang Y, Sheng L, Zhang H, Du X, An C, Xia X, Xia XL, Chen FD, Jiang JF, Chen SM (2017) CmMYB19 over-expression improves aphid tolerance in Chrysanthemum by promoting lignin synthesis. Int $\mathrm{J}$ Mol Sci 18: 1-13.

52. Zhai Y, Li P, Mei Y, Chen M, Chen X, Xu H, Zhou X, Dong H, Zhang CL, Jiang WH, (2017) Three MYB genes co-regulate the phloem-based defence against English grain aphid in wheat. J Exp Bot68: 4153-4169. 
53. Shen XJ, Wang YY, Zhang YX, Guo W, Jiao YQ, Zhou XA (2018) Overexpression of the Wild Soybean R2R3-MYB Transcription Factor GsMYB15 Enhances Resistance to Salt Stress and Helicoverpa Armigera in Transgenic Arabidopsis. Int J Mol Sci 19: 3958.

54. Zhu G, Li W, Zhang F, Guo W (2018). RNA-seq analysis reveals alternative splicing under salt stress in cotton, Gossypium davidsonii. BMC genomics, 19: 1-15.

55. Li P, Song A, Gao C, Jiang J, Chen S, Fang WM, Zhang F, Chen FD (2015) The over-expression of a chrysanthemum WRKY transcription factor enhances aphid resistance. Plant Physiol Bioch 95: 2634.

56. Kloth KJ, Wiegers GL, Busscher-Lange J, van Haarst JC, Kruijer W, Bouwmeester HJ Dicke M, Jongsma MA, Notes A (2016) AtWRKY22 promotes susceptibility to aphids and modulates salicylic acid and jasmonic acid signalling. J Exp Bot67: 3383-3396.

57. Hu L, Ye M, Li R, Zhang T, Zhou G, Wang Q, Lu J, Lou YG (2015) The rice transcription factor WRKY53 suppresses herbivore-induced defenses by acting as a negative feedback modulator of map kinase activity. Plant physiol163:2907-2091.

58. Bhattarai KK, Li Q, Liu Y, Dinesh-Kumar SP, Kaloshian I (2007) The Mi-1-mediated pest resistance requires Hsp90 and Sgt1. Plant Physiol 144: 312-323.

59. Atamian HS, Eulgem T, Kaloshian I (2012) SIWRKY7O is required for Mi-1-mediated resistance to aphids and nematodes in tomato. Planta 235: 299-309.

60. Bhattarai KK, Atamian HS, Kaloshian I, Eulgem T (2010) WRKY72-type transcription factors contribute to basal immunity in tomato and Arabidopsis as well as gene for-gene resistance mediated by the tomato R gene Mi-1. Plant J63: 229-240.

61. Mantelin S, Peng HC, Li B, Atamian H S, Takken FL, Kaloshian I (2011) The receptor-like kinase SISERK1 is required for Mi-1-mediated resistance to potato aphids in tomato. Plant J 67: 459-471.

62. Vincent TR, Avramova M, Canham J, Higgins P, Bilkey N, Mugford ST, Pitino M, Toyota M, Gilroy S, Miller AJ, Hogenhout SA, Sanders D (2017) Interplay of plasma membrane and vacuolar ion channels, together with BAK1, elicits rapid cytosolic calcium elevations in Arabidopsis during aphid feeding. Plant Cell 29: 1460-1479.

63. Aidemark M, Andersson CJ, Rasmusson AG, and Widell S (2009) Regulation of callose synthase activity in situ in alamethicin-permeabilized Arabidopsis and tobacco suspension cells. BMC Plant Biol9:27, 1-12.

64. Furch AC, van Bel AJ, Fricker M D, Felle HH, Fuchs M, Hafke JB (2009) Sieve element $\mathrm{Ca}^{2+}$ channels as relay stations between remote stimuli and sieve tube occlusion in Vicia faba. Plant Cell 21: 21182132.

65. Louis J, Leung Q, Pegadaraju V, Reese J, Shah J (2010) PAD4-dependent antibiosis contributes to the ssi2-conferred hyper-resistance to the green peach aphid. MolPlant Microbe Interact 23: 618-627.

66. Louis J, Leung Q, Pegadaraju V, Reese J, Shah J (2010) Discrimination of Arabidopsis PAD4 activities in defense against green peach aphid and pathogens. Plant Physiol 158: 1860-1872. 
67. Pegadaraju V, Knepper C, Reese J, Shah J (2005) Premature leaf senescence modulated by the Arabidopsis PHYTOALEXIN DEFICIENT4 gene is associated with defense against the phloem-feeding green peach aphid. Plant Physiol 139: 1927-1934.

68. Louis J, Gobbato E, Mondal H, Feys BJ, Parker JE, Shah, J. (2012) Discrimination of Arabidopsis PAD4 activities in defense against green peach aphid and pathogens. Plant Physiol158: 1860-1872.

69. Pegadaraju V, Louis J, Singh V, Reese JC, Bautor J, Fey BJ, Cook G, Parker JE, Shah J (2007) Phloembased resistance to green peach aphid is controlled by Arabidopsis PHYTOALEXIN DEFICIENT4 without its signaling partner ENHANCED DISEASE SUSCEPTIBILITY1. Plant J 52: 332-341.

70. Mondal HA, Louis J, Archer L, Patel M, Nalam VJ, Sarowar S, Sivapalan V, Root DD, Shah J (2018) Arabidopsis ACTIN-DEPOLYMERIZING FACTOR3 is required for controlling aphid feeding from the phloem. Plant Physiol176: 879-890.

71. Leng N, Dawson JA, Thomson JA, Ruotti V, Rissman Al, Smits BM, Haag JD, Gould MN, Stewart RM, Kendziorski C (2013) EBSeq: An empirical Bayes hierarchical model for inference in RNA-Seq experiments. Bioinformatics 29: 1035-1043.

72. Deng YY, Li JQ, Wu SF, Zhu YP, Chen YW, He FC (2006) Integrated nr database in protein annotation system and its localization. Comput En 32: 71-74.

73. Apweiler R, Bairoch A, Wu CH, Barker WC, Boeckmann B, Ferro S, Gasteiger E, Huang HZ, Lopez R, Magrane M, Martin MJ, Natale DA, O'Donovan C, Redaschi N, Yeh LL (2004) UniProt: the Universal Protein knowledgebase. Nucleic Acids Res 32: 115-119.

74. Ashburner M, Ball CA, Blake JA, Botstein D, Butler H, Cherry JM (2000) Gene Ontology: tool for the unification of biology. Nat Genet 25: 25-29.

75. Tatusov RL, Galperin MY, Natale DA, Koonin EV (2000) The COG database: a tool for genome-scale analysis of protein functions and evolution. Nucleic Acids Res28: 33-36.

76. Kanehisa M, Goto S, Kawashima S, Okuno Y, Hattori M (2004) The KEGG resource for deciphering the genome. Nucleic Acids Res32: 277-280.

77. Pfaffl MW (2001) A new mathematical model for relative quantification in real-time RT-PCR. Nucleic Acids Res 29: 45-45.

\section{Table}


Tab.The number and percentage of annotated new genes against the six databases

\begin{tabular}{|c|c|c|c|}
\hline & Annotated databases & Number & percent \\
\hline 1 & COG_Annotation & 1263 & $14 \%$ \\
\hline 2 & GO_Annotation & 3352 & $37 \%$ \\
\hline 3 & KEGG_Annotation & 2044 & $22 \%$ \\
\hline 4 & KOG_Annotation & 4308 & $47 \%$ \\
\hline 5 & Pfam_Annotation & 2836 & $31 \%$ \\
\hline 6 & Swissprot_Annotation & 4286 & $47 \%$ \\
\hline 7 & eggNOG_Annotation & 6279 & $69 \%$ \\
\hline \multirow[t]{3}{*}{8} & nr_Annotation & 7482 & $82 \%$ \\
\hline & All_Annotated unigenes & 7510 & $83 \%$ \\
\hline & total new genes & 9103 & $100 \%$ \\
\hline
\end{tabular}

Figures

A

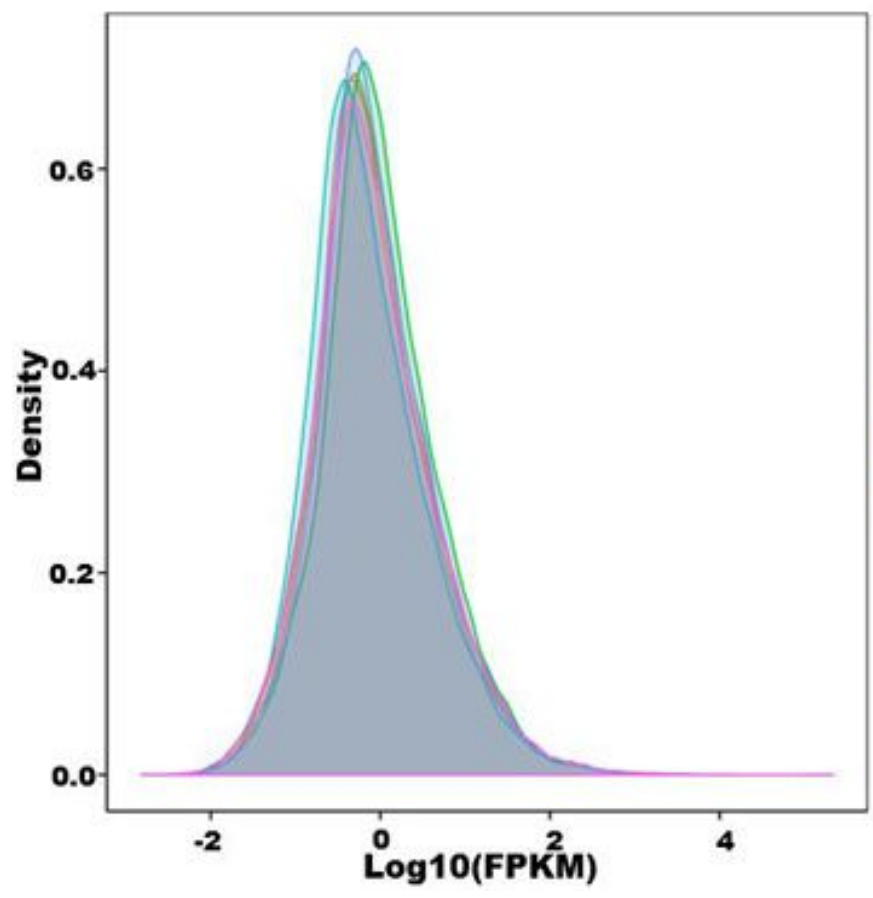

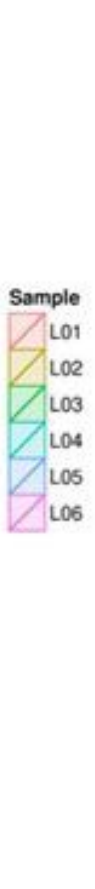

B

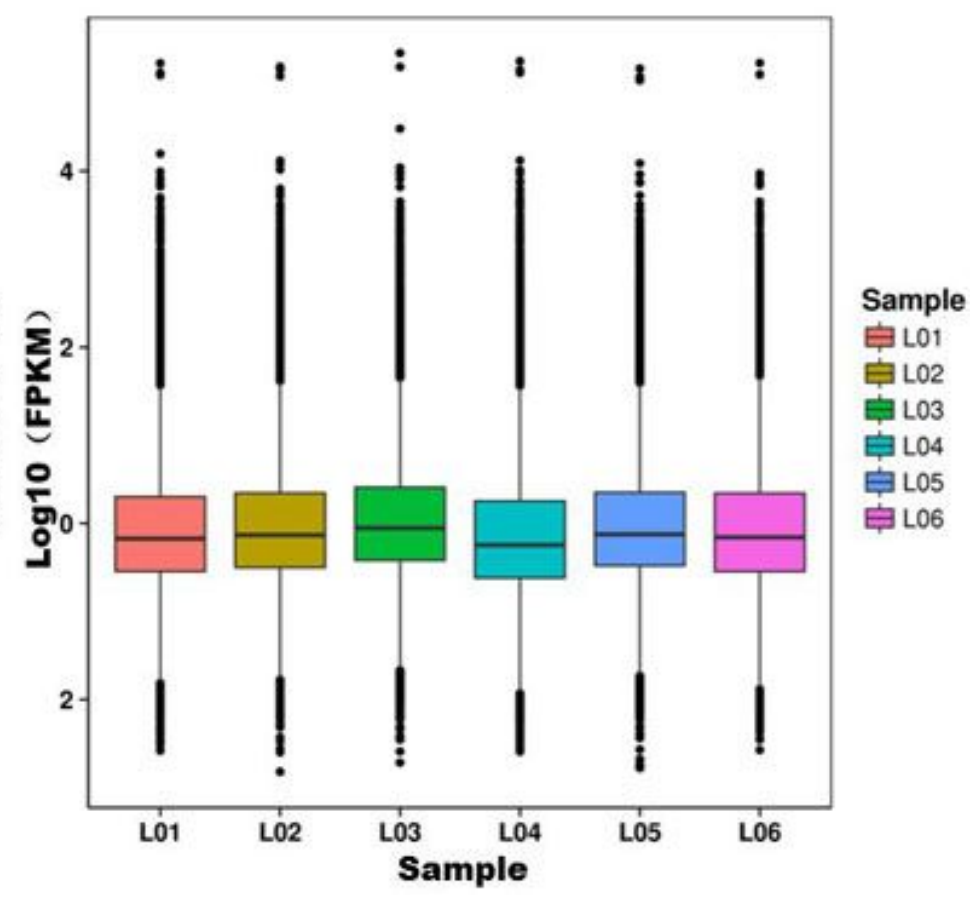

Figure 1

FPKM analysis in six sample RNA-Seq. $\triangle A \triangle \triangle$ Comparison of FPKM density distribution. $\triangle \mathrm{B} \bigotimes$ FPKM box plot. L01. 0 h: CK (without cotton aphid damage), L02: 6 h, L03: 12 h, L04: 24 h, L05: 48 h. L06: 72 h. 
A

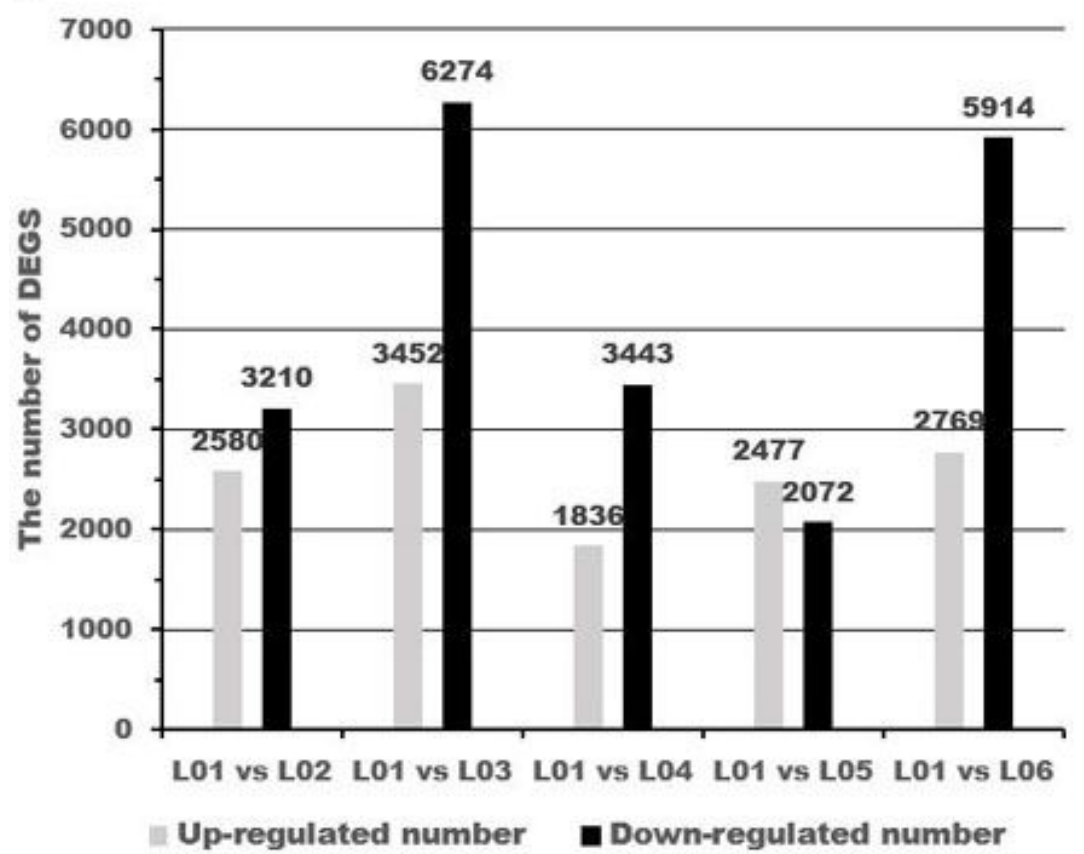

B

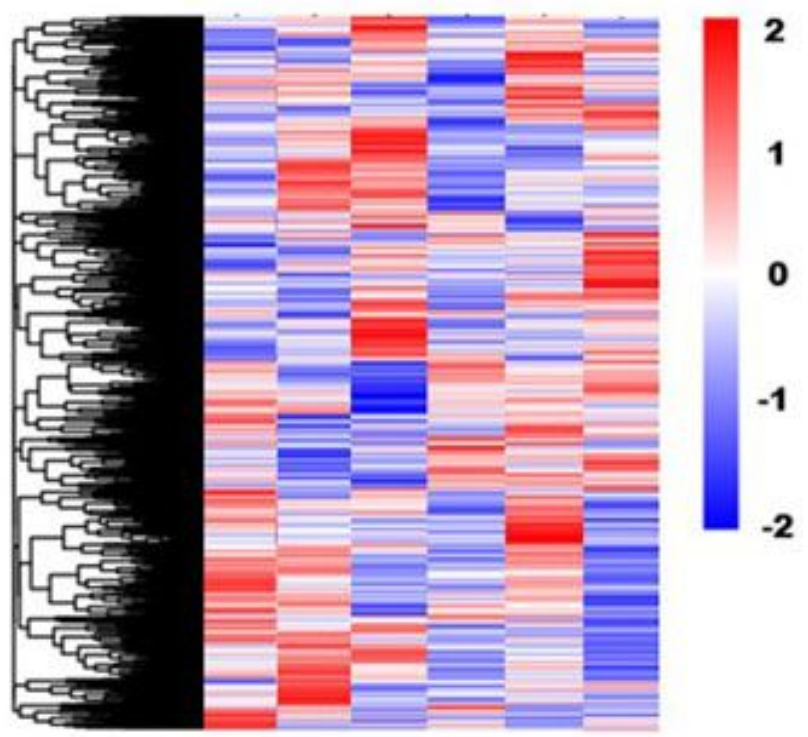

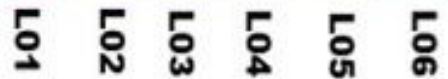

\section{Figure 2}

Analysis of differentially expressed genes of cotton leaves between cotton aphid damage and CKखL01》at the different time points. (A) Analysis of the number of differentially expressed genes. (B) The cluster diagram of differentially expressed genes. Different columns in the Fig. B represent different samples, and different rows represent different genes. Color represents the level of gene expression in the sample. L01: CK, L02: 6 h, L03: 12 h, L04: 24 h, L05: 48 h, L06: 72 h.

A

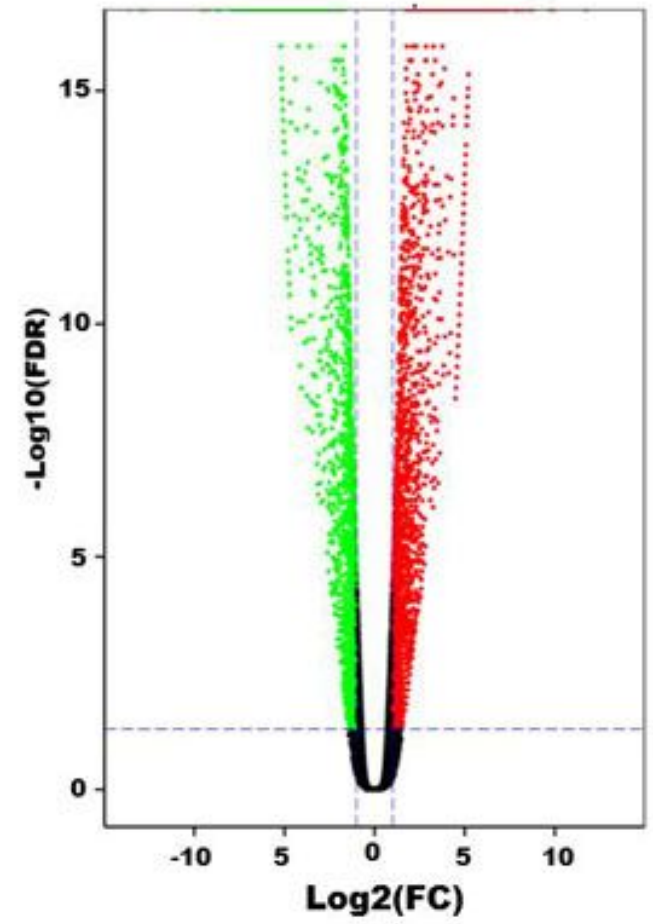

B

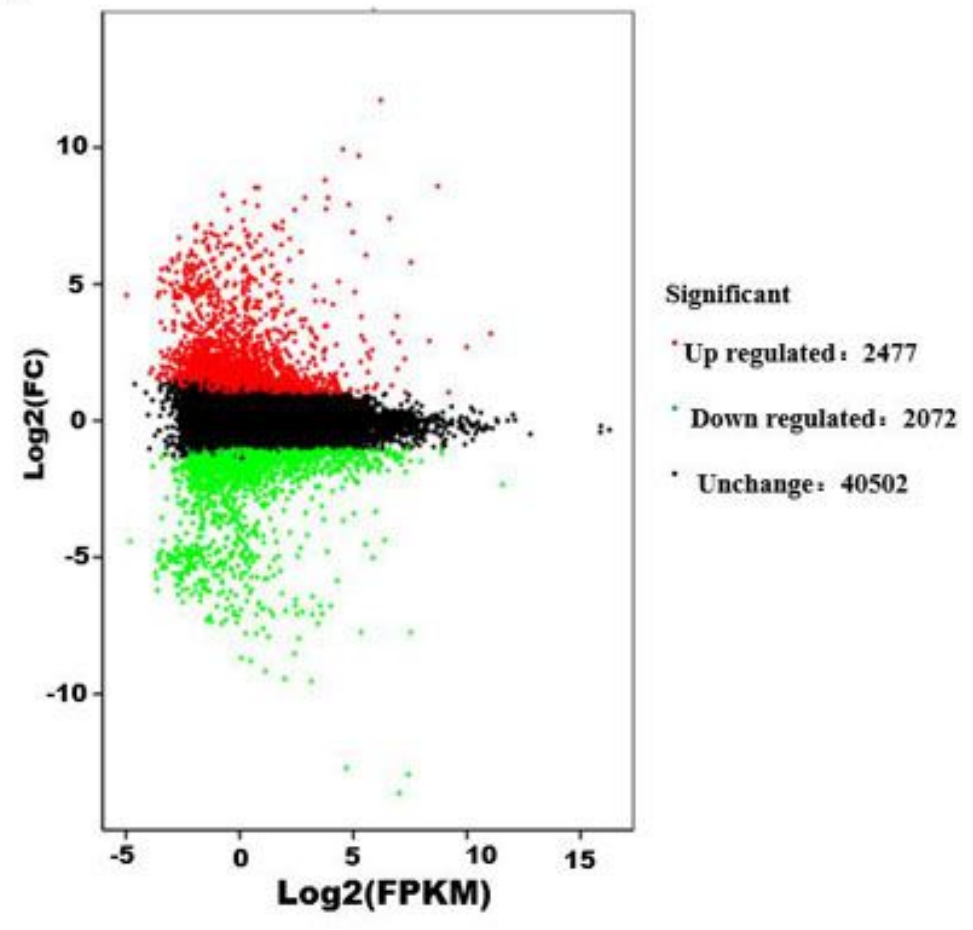

Figure 3 
Analysis of differentially expressed genes of cotton leaves between cotton aphid damage $\mathbb{4} 48 \mathrm{~h} \rrbracket a n d \mathrm{CK}$ $\varangle 0 \mathrm{~h} \rrbracket$. (A) The Volcano plot. (B) MA plot. The green dots represent down-regulated differentially expressed genes, the red dots represent up-regulated differentially expressed genes, and the black dots represent non-differentially expressed genes.

A

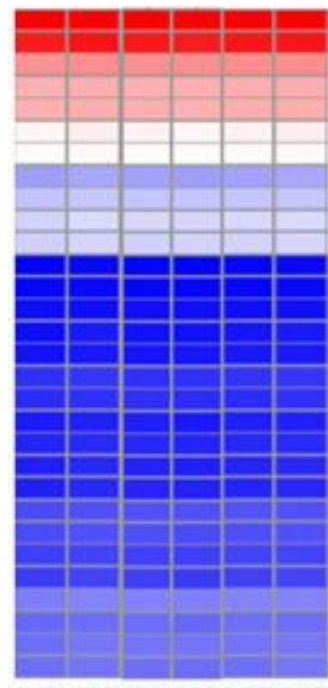

L01 L02 L03 L04 LOSLO6

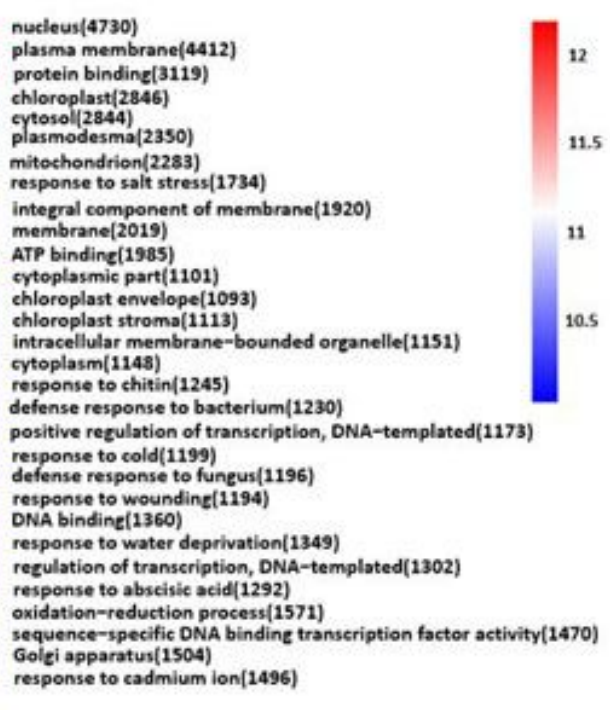

plasma membrane(4412)

protein binding [3119)

plasmodesma(2350)

response to salt stress(1734)

integral component of membrane(1920)

ATP bindine[1985)

cytoplasmic part(1101)

Chloroplast envelope(1093)

intracellular membrane-bounded organelle[1151]

Cyoplasm(1148)

defense response to bacterium(1230)

positive regulation of transeription, DNA-templated(1173)

(1)

ONA bindine(1360)

reculation of transcription, DNA-te

oxidation-reduction process(1571)

Golgi apparatus (1504)

response to cadmium ion(1496)
B

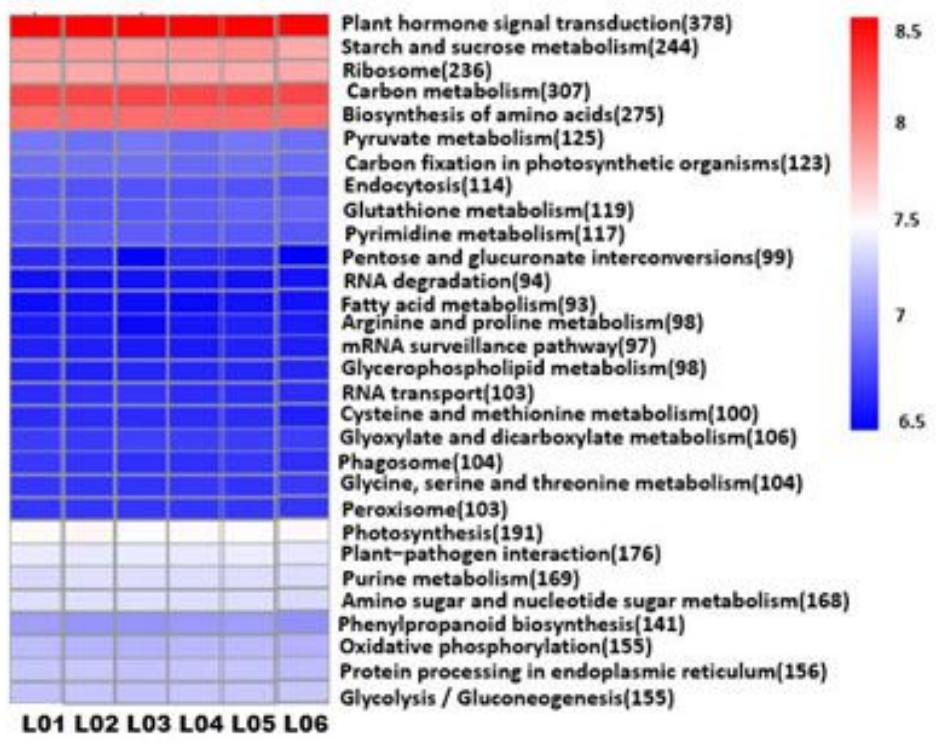

Figure 4

Analyses of DEGs under cotton attack at different time points. (A) GO rich clustering class diagram of the total differentially expressed genes. red indicates the classification of high expression function, while blue indicates the term with relatively low expression. The parenthesis after each term label is the number of genes containing significant differences for that term. (B) The KEGG rich cluster class diagram of the total differentially expressed genes. Red indicates high expression functional classification, while blue indicates relatively low expression metabolic pathways. Each metabolic pathway is labeled with the number of genes containing significant differences within the metabolic pathway in parentheses. 
A

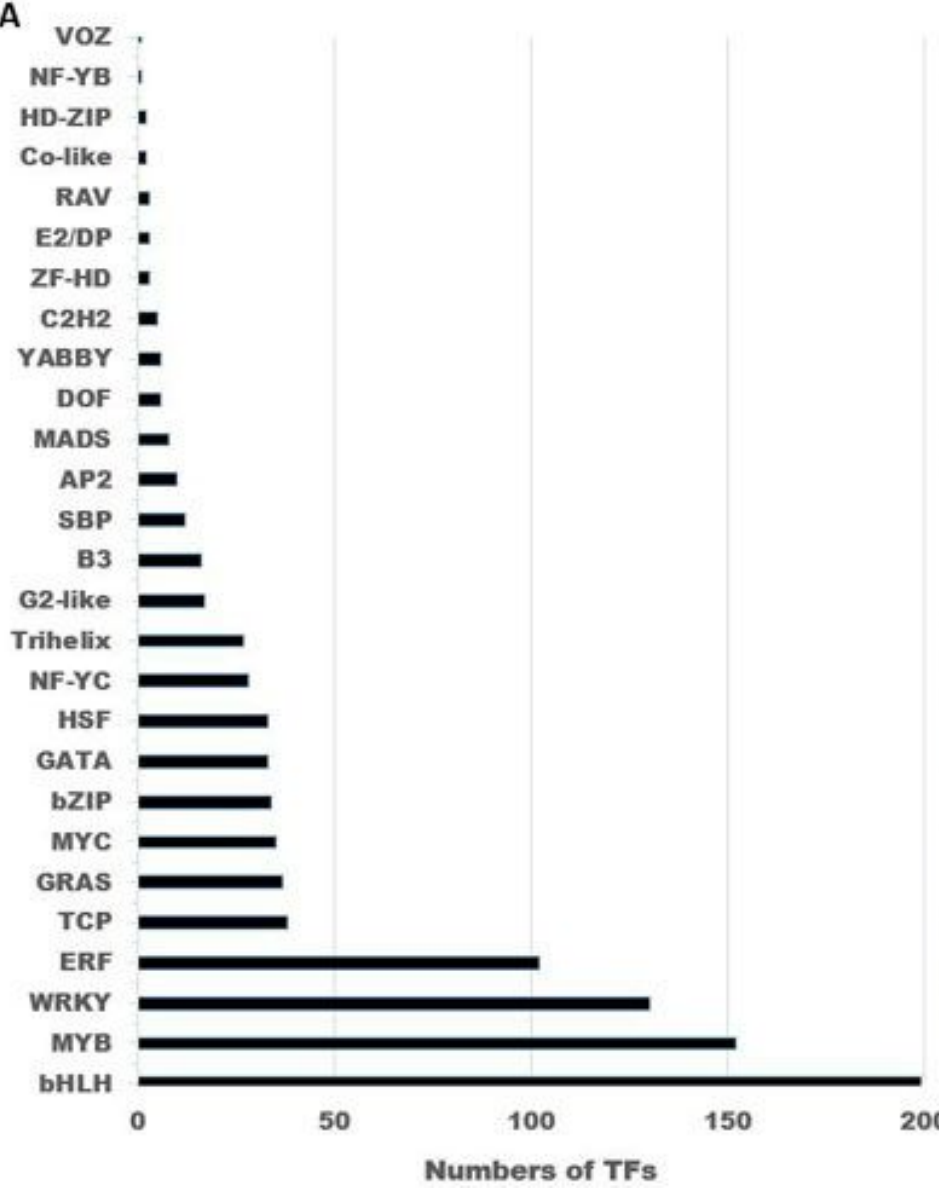

B

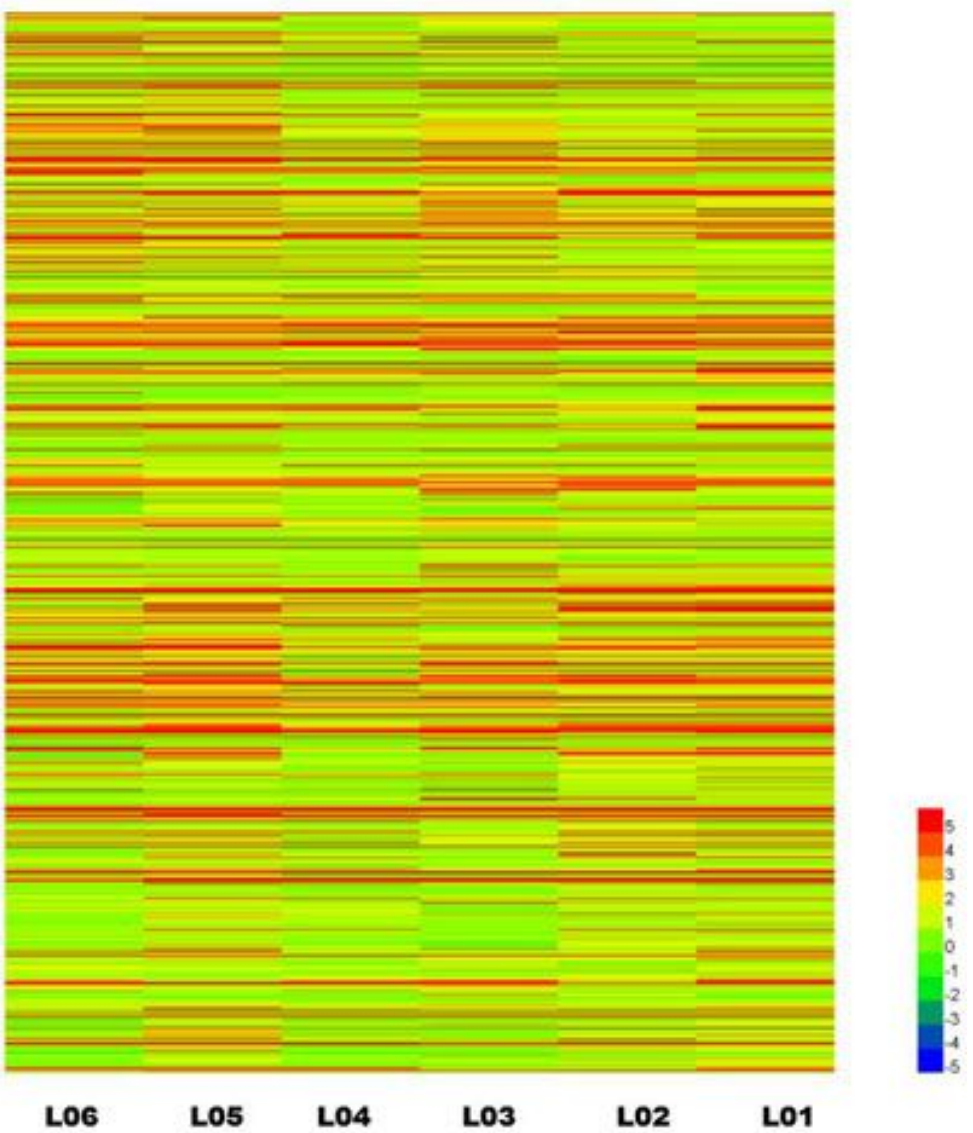

Figure 5

Number distribution and expression of differentially expressed transcription factors from different families. (A) Number distribution of the differentially expressed transcription factors. (B) Expression values of differentially expressed transcription factors that were more than 30 . Their expression values are presented as FPKM-normalized log2-transformed counts. L01: CK, L02: 6 h, L03: 12 h, L04: 24 h, L05: 48 h, L06: 72 h. 
A

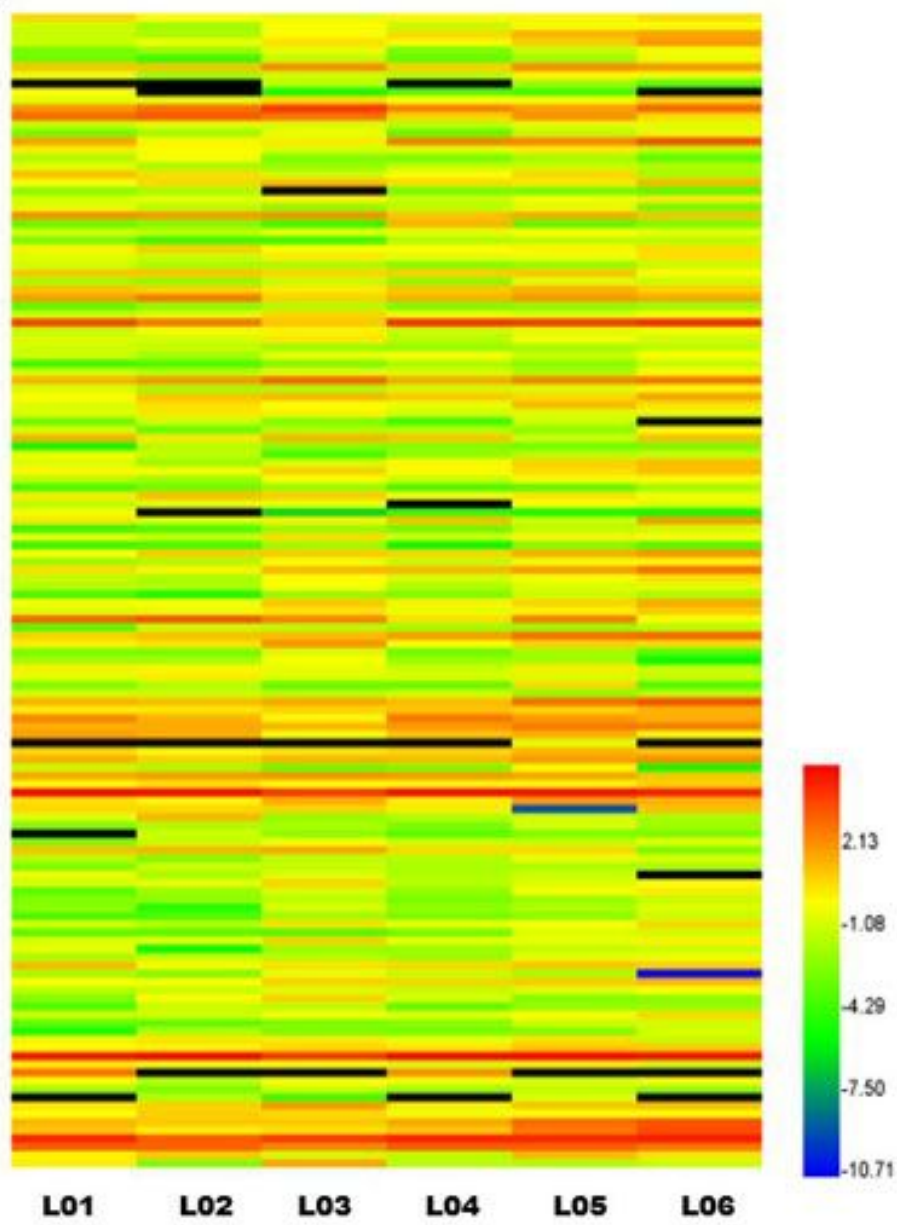

B

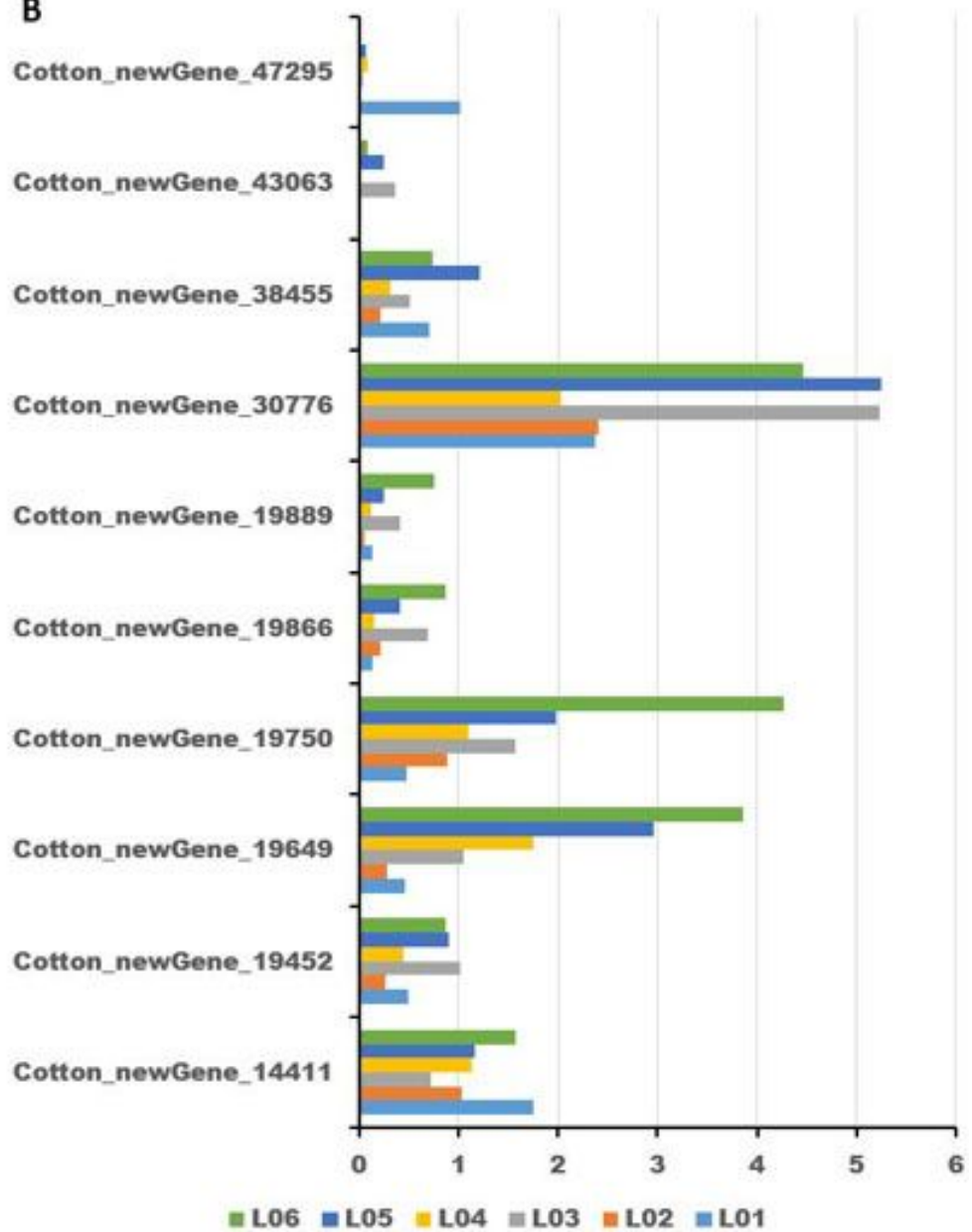

Figure 6

Expression of differentially expressed lectins at different time points under cotton aphid attack. (A) Expression analysis of all differentially expressed lectins. (B) Expression values of 10 differentially expressed new lectins. Their expression values are presented as FPKM-normalized log2-transformed counts. 

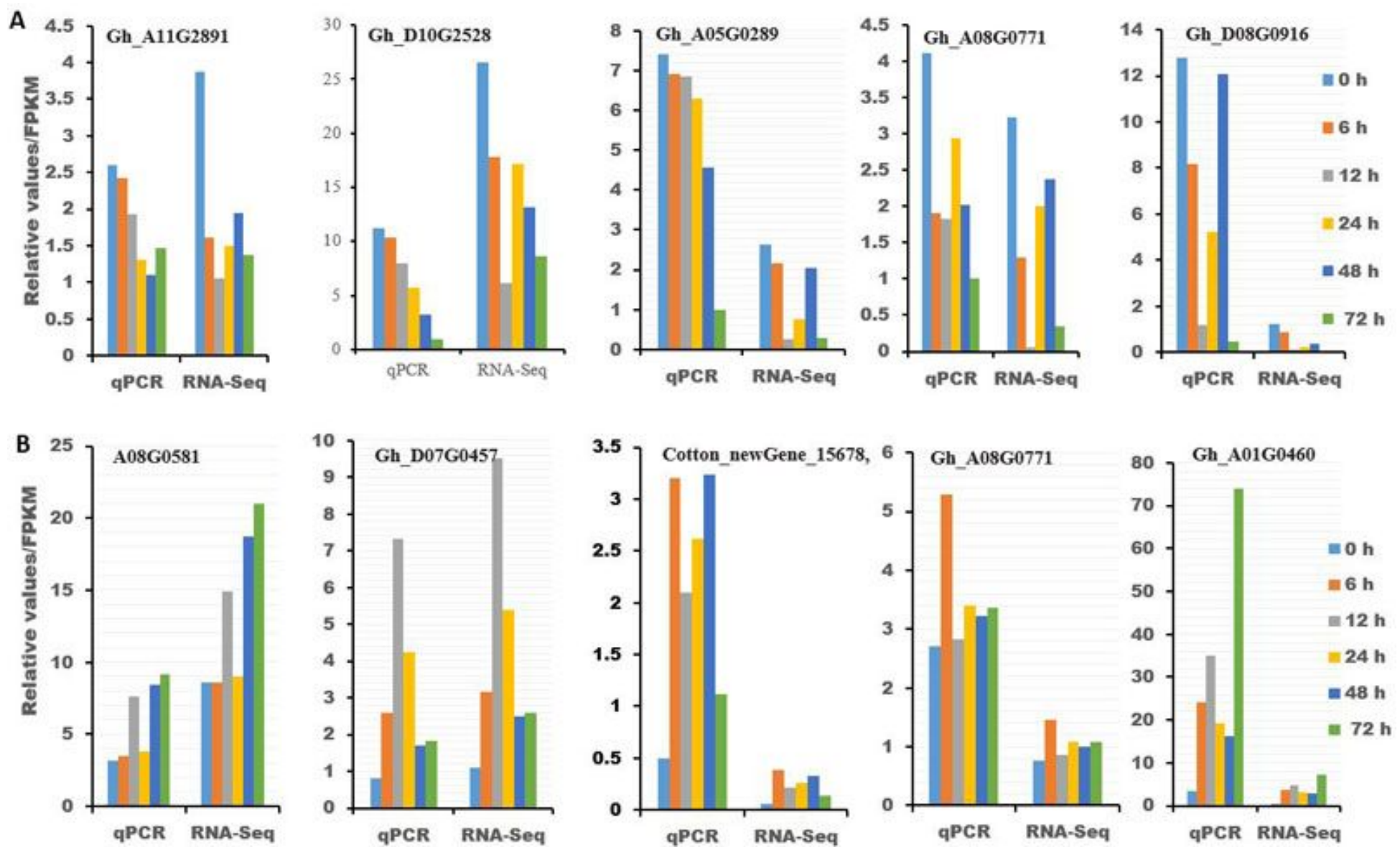

Figure 7

Expression level of ten selected DEGs in cotton response to aphid infestation over time $(0,6,12,24,48$ and $72 \mathrm{~h}$ ) using qPCR and RNA-Seq methods. A Expression level of five up-regulated DEGs. B Expression level of five down-regulated DEGs. The $0 \mathrm{~h}$ time point (no aphid infestation) serves as a control. Relative values was calculated based on the 2- $\triangle \triangle \mathrm{Ct}$ method using GhUBI as the reference gene for qPCR, and three biological replicates and three technical replicates were performed. Five down-regulated DEGs are as follows: Gh_A11G2891, Gh_D10G2528, Gh_A05G0289, Gh_A08G0771, Gh_D08G0916. Five upregulated DEGs are as follows: Gh_A08G0581, Gh_D07G0457, Gh_A03G0199, Cotton_newGene_15678, Gh_A01G0460.

\section{Supplementary Files}

This is a list of supplementary files associated with this preprint. Click to download.

- supplement1.xls

- supplement2.xls

- supplement3.xls

- supplement4.xls

- supplement5.xls 
- supplement6.xls

- supplement7.xls 